Est Ag 54 (2019) 617-639

\title{
El espíritu del Pacto de las Catacumbas y la Teología de la Liberación
}

ORLANDO IBARRA, OSA

RESUMEN: El presente artículo, busca evidenciar que el Pacto de las Catacumbas es el sello místico del Vaticano II, y que la Pobreza evangélica anclada en la ortopraxis, es el argumento espiritual más profundo que atraviesa toda preocupación en la Teología de la Liberación. El compromiso de aquellos obispos que firmaron dicho pacto, es contundente y desafiante para el colegio episcopal actual ante la humanidad herida, que, en su grito silencioso, reclama austeridad es sus pastores; Francisco en su magisterio, habla permanentemente de ello. Finalmente, el trabajo acerca a una lectura espiritual que lleva al Pacto a partir de la herencia del obispo de Hipona, en la escuela agustiniana de la Amerindia.

Palabras ClaVe: Pacto, Mística, Espiritualidad, Pobreza, Ortopraxis.

ABSTRACT: The present article seeks to show that the Pact of the Catacombs is the mystical seal of Vatican II, and that evangelical Poverty anchored in orthopraxy is the deepest spiritual argument that going through every preoccupation in Liberation Theology. The commitment of those bishops who signed this pact, is forceful and challenging for the present episcopal college in the face of wounded humanity, which, in its silent cry demands austerity from its pastors; Pope Francis, in his magisterium, speaks permanently of it.

${ }^{1}$ El presente artículo es elaborado por Fray Jesús Orlando Ibarra Ochoa, OSA., candidato al doctorado en Teología por la Pontificia Universidad Javeriana de Bogotá. El trabajo se realiza bajo la evaluación del Padre Dr. Ignacio Madera, SDS. Orlando Ibarra es Magister en Teología por la Pontificia Universidad Javeriana y Teólogo en pregrado por la Fundación Universitaria Cervantes de los frailes agustinos en Colombia. Es profesor de Teología en la misma Universidad. 
Finally, the work approaches a spiritual reading that leads to the Pact from the inheritance of the bishop of Hippo, in the Augustinian school of the Amerindian.

KEYwORDs: Pact, Mystic, Spirituality, Poverty, Orthopraxy.

\section{Introducción}

La pobreza de la que el Señor Jesucristo sentenció que siempre existirá mientras haya injusticia en el corazón del ser humano es el lugar teológico del presente artículo. El cambio de paradigma en la mirada de la Iglesia hacia los pobres a través de un grupo de 40 obispos preocupados por la pobreza en la humanidad desembocó en un hecho concreto días antes de clausurar el Concilio Vaticano II, llamado "Pacto de las Catacumbas"2.

Es conocido el contexto histórico del Concilio en el que la famosa escuadra belga, ${ }^{3}$ apoyada por el cardenal Giacomo Lercaro ${ }^{4}$, arzobispo de

${ }^{2}$ Xavier Pikaza - José Antunes Da Silva (eds.), El Pacto de las Catacumbas, Estella: Editorial Verbo Divino, $2^{\mathrm{a}}$ reimpresión, 2015. El texto completo del Pacto además del libro conmemorativo se encuentra en la página web de la Conferencia Episcopal de Chile, el referente teológico en tal página es relevante:

http://documentos.iglesia.cl/documento.php?id=4149

${ }^{3}$ La expresión "squadra belga" según algunos datos de la historia del Vaticano II fue dada por periodistas que hacían el cubrimiento del Concilio durante el tiempo en que se realizó, el artículo de Mathijs Lamberigts y Leo Declerck nos regala un dato muy interesante: "Cependant, à partir de la 2e session, la presse italienne commença à parler d'une squadra belga aussi redoutable que la squadra azurra, l'équipe nationale du football italien. Cette squadra belga occupait en effet une place dominante aussi bien au sein de la direction générale du concile (...) De plus le Pontificio Collegio Belga était vu comme un centre stratégique où étaient élaborées les manoeuvres de la «majorité» conciliaire. Certains parlaient même d'un Concilium Vaticanum ii, Lovaniense i ou d'un Concilium Mechliniense, Romae habitum". (En: Lamberigts, Mathijs - Declerck, Leo, "La contribution de la «squadra belga» au Concile Vatican II. Anuario de Historia de la Iglesia”, [S.1.], v. 21, p. 157183, jul. 2015. Disponible en:

$<$ https://www.unav.edu/publicaciones/revistas/index.php/anuario-de-historia-iglesia/article/view/2306>. (Consultado el 12 nov. 2017).

${ }^{4}$ Santiago Madrigal hablando del cardenal Lercaro en su estudio sobre el giro eclesiológico en la recepción de Vaticano II nos dice lo siguiente: "Desde su conocida trayectoria pastoral y su compromiso personal para con los más desfavorecidos, Lercaro había sido invitado a participar en los trabajos del pequeño grupo de padres y de peritos que se reunían en el Colegio Belga para profundizar en la relación entre la Iglesia, el Evangelio y 
Bolonia, elabora permanentes exhortaciones en torno a la pobreza como bienaventuranza que ha de adoptar todo pastor de la Iglesia, testimonio necesario en una época que padece los estigmas de la secularización y una abismal brecha entre la riqueza de los poderosos y los modernos esclavos sujetos a toda forma de injusta e inhumana pauperización.

Lo significativo del Pacto de las Catacumbas, como desarrollaremos a continuación, es su incidencia espiritual en la llamada Teología de la Liberación, el corazón del presente trabajo encuentra allí su punto de inspiración. Existe cierta espiritualidad en tal Pacto que delineó la mística de lo que posteriormente se consideró como la Teología Latinoamericana desarrollada por una Iglesia que ad portas de sus quinientos años de evangelización llegaba a su adultez y madurez.

Nuestra hipótesis radica en que la identidad mística de la Teología de la Liberación encuentra en el Pacto de las Catacumbas uno de los fundamentos de su génesis. Para intentar evidenciar tales axiomas y brindar nuestro aporte desarrollaremos el artículo en tres apartados: a) Contexto histórico y eclesial del Pacto de las Catacumbas. b) La espiritualidad del Pacto en la Teología de la Liberación y el Magisterio de Francisco. c) Un aporte de lectura al Pacto desde la espiritualidad agustiniana.

\section{a. Contexto histórico y eclesial del Pacto de las Catacumbas}

El 16 de noviembre de 1965 en las catacumbas de santa Domitila obispos después de la celebración eucarística firmaron el llamado Pacto

la pobreza (...). Lercaro se convirtió en el cardenal protector del proyecto «la Iglesia de los pobres» con su famoso discurso del 6 de diciembre de 1962, la antevíspera de la clausura de la primera etapa conciliar. Con claridad y brillantez sugirió que el centro focal del Concilio fuera una Iglesia que anuncia el Evangelio a los pobres”, en: Madrigal, Santiago, El giro eclesiológico en la recepción de Vaticano II, Maliaño, Sal Terrae, 2017, 262.

5 Pikaza, Xavier, "Presentación del libro conmemorativo", en: Xavier Pikaza - José Antunes Da Silva (eds.), El Pacto de las Catacumbas, 23. El número 40 en términos espirituales llama fuertemente la atención. Bien sabemos el significado bíblico de tal número, los cambios de una etapa a otra, aunque bíblicamente representan los años o los días (40 años peregrina el pueblo de Israel por el desierto y 40 días ayuna el Señor Jesucristo también en el desierto), la interpretación que brindamos del número de obispos representa el tiempo transcurrido, en desierto espiritual, como preparación a tan significativo acontecimiento, si Israel después de 40 años en medio de la prueba y su debilidad encuentra la Tierra de la promesa y el Señor después de 40 días probado en su humanidad a través de la tentación 
de las Catacumbas en el que a través de 13 numerales se comprometían a caminar con los pobres, ser una Iglesia no solo para los pobres sino de los pobres. Pikaza en la presentación del libro conmemorativo afirma que no hay una lista oficial de los obispos que firmaron el pacto, el argumento reside en que querían tener una celebración discreta lejos de la prensa y para evitar que su gesto de sencillez y compromiso fuera interpretado como una lección para los otros obispos. La noticia, según los estudios que se han realizado del Pacto, solo aparece unas semanas más tarde en un diario francés en la que no se dan nombres, estos se conocen por los apuntes de Monseñor Charles Marie Himmer, obispo de Tournai quien había presidido la celebración'. Según anota Luigi Betazzi, un mes antes del comienzo del Concilio Vaticano II, el 11 de septiembre de 1962, Juan XXIII a través de la radio proféticamente afirmó: "In faccia ai paesi sottosviluppati la Chiesa si presenta quale è, e vuol essere, come la Chiesa di tutti, e particolarmente la Chiesa dei poveri"’. Según el análisis de Betazzi tal afirmación permeó la conciencia de algunos pastores de la Iglesia universal que una vez llegados a las sesiones del Concilio le tuvieron como consigna, siendo el cardenal Lercaro el más insigne representante.

Las palabras del cardenal el 6 de diciembre de 1962 a los padres conciliares son sugestivas:

(...) questa è l'ora dei poveri, dei milioni di poveri che sono su tutta la terra, questa è l'ora del mistero della chiesa madre dei poveri, questa è l'ora del mistero di Cristo soprattutto nel povero (...). Se, come è stato detto [più volte] anche ieri [in quest'aula], il tema di questo concilio è la chiesa, si può e si deve precisare che la formulazione più conforme alla verità eterna del vangelo e insieme più adeguata alla situazione storica del nostro tempo è proprio questa: il tema del concilio è la chiesa, in quanto particolarmente chiesa dei

inicia su vida pública para llevar consuelo a su pueblo, en 40 obispos que representan el colegio episcopal encontramos la transición de una forma de Iglesia a otra, por analogía con Israel y con el Señor también la Iglesia llega a un punto de encuentro con la promesa en medio del reverso de la historia en palabras de Gustavo Gutiérrez.

${ }^{6}$ Ibid., 24.

${ }^{7}$ Juan XXIII, "Ai fedeli di tutto il mondo, a un mese dal Concilio Ecumenico Vaticano II". Vatican.va, 11 de septiembre de 1962,

http://w2.vatican.va/content/john-xxiii/it/messages/pont_messages/1962/documents/ hf_jxxiii_mes_19620911_ecumenical-council.html (Consultado el 12 de noviembre de 2017). 
poveri, di tutti i milioni e milioni di singoli uomini poveri, e collettivamente dei popoli poveri di tutta la terra8 .

Betazzi al realizar la radiografía del contexto eclesial describe que el cardenal Lercaro sintetizaba los temas y la preocupación de muchos pastores sensibilizados con este problema urgente propuesto a la Iglesia para la evangelización del mundo. Destaca, por ejemplo, la intervención del mismo obispo auxiliar de Lyon, monseñor Alfred Ancel: "la Iglesia aparece ante los pobres como una extraña o incluso como una adversaria, porque es rica y poderosa y está aliada con los ricos y los poderosos. (...) hemos entrado en un movimiento irresistible e irreversible. El Espíritu Santo ha inaugurado en la Iglesia de Dios una nueva etapa que estará marcada por una renovación profunda según el Evangelio".

Joan Planellas Barnosell en el artículo que reposa en el libro conmemorativo por los 50 años del Pacto elabora un rastreo del grupo que en el contexto histórico del Concilio Vaticano II se llamó Iglesia de los Pobres y que se encargó de ser la voz teológica del impulso hacia una Iglesia pobre. Destaca un primer núcleo formal de este grupo que se reúne por primera vez el 26 de octubre de 1962 en el colegio Belga de Roma por iniciativa de Paul Gauthier, sacerdote obrero de Nazaret ${ }^{10}$.

Planellas Barnosell destaca también la experiencia francesa de los curas obreros iniciada en París a principios de los años cuarenta y que aunque habían sido suprimidos en 1953 mantenían una significativa vitalidad en los albores del Concilio. De igual manera da relevancia a los obispos que habían amparado y puesto en marcha el grupo Iglesia de los pobres: Mons. Charles Himmer, obispo de Tournai-Bélgica, Mons. George Hakin, obispo melquita de Akka-Nazaret, Mons Georges Mercier, obispo de Laghouat-Argelia, conocedor de la espiritualidad de Charles de Foucauld, Mons. Alfred Ancel, obispo auxiliar de Lyon (había sido cura obrero de los suburbios de esta misma ciudad), Mons. Pierre Gerlier, arzo-

${ }^{8}$ Lercaro, Giacomo, "Per la forza dello Spirito. Discorsi Conciliari”. Disponible en: http://teospi.altervista.org/ 2Sem2010.11/Chiesa_e_povert___-_card._G._Lercaro_-_6_dicembre_1962.pdf (Consultado el 12 de noviembre de 2017)

${ }_{9}$ Bettazzi, Luigi, "Iglesia de los pobres”, en: Xavier Pikaza - José Antunes Da Silva (eds.), El Pacto de las Catacumbas, 40.

${ }^{10}$ Planellas, Joan, "Los artífices del Pacto", en: Xavier Pikaza - José Antunes Da Silva (eds.), El Pacto de las Catacumbas, 84. 
bispo de Lyon y Mons. Giacomo Lercaro, arzobispo de -Bolonia. A nivel latinoamericano destaca especialmente la participación de Mons. Helder Camara de Brasil y Mons. Manuel Larraín de Chile como representantes del CELAM ${ }^{11}$.

Los anteriores obispos fueron los encargados de amparar las proféticas palabras de Juan XXIII, Norbert Arntz elabora una importantísima conclusión que a continuación transcribimos literalmente dado el peso de su apreciación:

¿Por qué la abrumadora mayoría de los obispos carecía de interés por tratar el problema de la pobreza? No hay para esa pregunta una respuesta clara y satisfactoria. Muchos dicen que la mayoría de los obispos pertenecía a una cultura burguesa y estaba marcada por ella, estaba modernizada y había aceptado los postulados de la sociedad burguesa, los derechos humanos, la separación de Iglesia y Estado, pero no conocía el problema de las diferencias de clase (...). El problema de la pobreza seguía considerándose todavía desde la perspectiva de las sociedades europeas occidentales. Los otros continentes apenas comenzaban a tomar consciencia de sus venas abiertas ${ }^{12}$.

Es en este punto donde encontramos un significativo argumento teológico - espiritual que ayuda a darle forma a la intuición inicial de nuestro trabajo: ya agotadas las mediaciones deliberativas por parte de los padres conciliares respecto de las intervenciones presentadas por el grupo Iglesia de los pobres y habiendo calado tal preocupación en el corazón de algunos de los allí presentes, a poco de clausurar el Concilio Vaticano, quizá en medio del cansancio y la fatiga, en profunda humildad y lleno el corazón de Fe, Caridad y Esperanza se congregan estos 40 obispos en las catacumbas de Domitila para dar un sello espiritual en el ámbito de lo místico y que radicaliza, en palabras de Pikaza, la gran reforma que propone Vaticano II: "este pacto asume la tradición universal del Nuevo Testamento y del principio de la Gran Iglesia, representada en Roma por las catacumbas, cuando aún no había basílicas o casas reales (...). Este gesto de los obispos puede parecer inocente, y lo es de alguna forma, pero se

${ }^{11}$ Ibíd., 86 - 88

12 Arntz, Norbert. "Por una Iglesia servidora y pobre", en: Xavier Pikaza - José Antunes Da Silva (eds.), El Pacto de las Catacumbas, 116. 
trata al mismo tiempo de un gesto muy provocador, en una línea de intensa protesta" 13 .

En todo el análisis que realiza Pikasa de las citas bíblicas presentes en el Pacto destacamos de su aporte que el Pacto es un intento de interpretar todo el Concilio desde la perspectiva de la pobreza, un evangelio de la pobreza dividido en doce momentos ${ }^{14}$. Afirma que desde la perspectiva del Nuevo Testamento estos obispos descubrieron, con admiración y entusiasmo que antes que obispos eran cristianos, y que para ser cristianos tenían que asumir plenamente el Sermón de la Montaña, con la llamada radical de Jesús a la pobreza:

Durante siglos, un tipo de Iglesia había dado la impresión de que la pobreza evangélica era una virtud especial, propia de algunos mendicantes y cristianos particulares, que habían optado por ella por compromiso o mérito especial, como algo añadido, que solo importaba para algunos perfectos, sin que fuera necesario aplicarla a toda la Iglesia. Más aún, muchos pensaban que los obispos, por su especial dignidad, quedaban de alguna forma vinculados a la clase alta de la población, al ordo de senadores, terratenientes y nobles, como dirigentes no solo evangélicos, sino también político-sociales de sus comunidades (...). La pobreza era para otros ${ }^{15}$.

A propósito de los quinientos años de la Reforma Luterana, pasaron casi cinco siglos para aceptar con razón muchas de las críticas del fraile agustino respecto de lo ostentoso de una considerable parte de los eclesiásticos en su época. Dado que el Pacto es un sello místico al Vaticano II en clave de Pobreza, en este punto es menester destacar el diálogo ecuménico como uno de los grandes logros del siglo XX a nivel de Iglesias cristianas, lejos de pretensiones de absolutismos en la Verdad, encontramos un signo evidente de humildad que ha dado pasos gigantescos en el reconocimiento de la alteridad, reconocimiento que se ve reflejado en el discernimiento de la Teología de la Liberación y que a continuación abordaremos como parte de nuestro segundo apartado.

${ }^{13}$ Xavier Pikaza, "Un Pacto Bíblico", en: Xavier Pikaza - José Antunes Da Silva (eds.), El Pacto de las Catacumbas, 56 - 58.

${ }^{14}$ Ibíd., 61.

${ }^{15}$ Ibíd., 79. 


\section{b. La espiritualidad del Pacto que subyace en la Teología de la Liberación y el Magisterio de Francisco}

La recepción de la teología conciliar de Vaticano II por parte de los padres conciliares latinoamericanos fecundó las líneas teológicas de la Conferencia de Medellín en 1968, pero antes de este esencial acontecimiento en la irrupción de la Teología Latinoamericana de la Liberación, Norbert Arntz en el libro conmemorativo de los cincuenta años del Pacto que hemos venido trabajando nos regala un dato interesantísimo. Afirma que Mons. Helder Camara urgió al Papa Pablo VI a prometer una encíclica sobre el tema del desarrollo de los pueblos dado que las expectativas de los países del entonces llamado Tercer Mundo en los documentos del Concilio quedaban al margen de una ortopraxis eficaz, es por eso que el Papa Pablo VI elabora la encíclica Populorum progressio de 1967 que llevó a un manifiesto de dieciocho obispos tercermundistas y la posibilidad real de la experiencia del Concilio en Latinoamérica a través de la Conferencia de Medellín al año siguiente ${ }^{16}$.

Es conocido para la comunidad académica la génesis de la Teología de la Liberación, Medellín es uno de los principales referentes, asumido como tal, la línea espiritual que atraviesa su teología es por lo tanto el Pacto de las Catacumbas, su prioridad es la Justicia y este es el principal argumento en contra del prejuicio "ideologización de la pobreza" por parte de los detractores de la teología latinoamericana. Dada la eclosión de contemporáneos estudios sobre el problema del lenguaje en el análisis exegético y hermenéutico de la Sagrada Escritura, comprendemos que la acepción adecuada sobre la Pobreza atañe a la kénosis del Señor, anonadamiento o abajamiento que trae como principal consecuencia la caridad oblativa que busca la Justicia y que en argumentos teológicos latinoamericanos llamamos ortopraxis, premisa sine qua non sería posible elaborar nuestra teología.

El escrito de Clodovis Boff en el año 1990 sobre la epistemología y método de la Teología de la Liberación ${ }^{17}$ evidencia una clara postura en la búsqueda de senderos y en la consolidación de la identidad de nuestra lati-

${ }^{16}$ Arntz, "Por una Iglesia servidora y pobre", 118.

${ }^{17}$ Boff, Clodovis, "Epistemología y Método de la Teología de la Liberación”, en: Ellacuría, Ignacio - Jon Sobrino, Mysterium Liberationis. Conceptos fundamentales de la Teología de la Liberación, Madrid: Trotta, 1990, 79-114. 
noamericana teología. Quizá hoy muchos nos podemos sentir orgullosos de tal identidad, sin embargo, el camino espinoso que ha tenido que transitar la Teología de la Liberación para heredarnos la pluralidad de sus facetas (afro, indígena, feminista, ecoteológica, etc.) ha sido complejo, nos basta con recordar las mismas instrucciones de la Congregación para la Doctrina de la Fe en sus documentos de 1984 y 1986 que con un delicado juicio de valor cataloga a muchos sacerdotes, religiosas, religiosos y colaboradores pastorales como incapaces de precisar su contenido poniendo en circulación un conjunto de "ideas ruinosas para la fe"18 y que desembocan en la "perversión del cristianismo"19 al hacer uso del análisis marxista porque tiene como objetivo de su preocupación la historia misma, no en sentido dualista de historia de salvación e historia profana, sino una sola historia ${ }^{20}$, la historia de los hombres ${ }^{21}$ por la que el Verbo eterno se hizo uno de nosotros.

Lejos de comparar al Señor Jesucristo con grandes pensadores, pero intentando plasmar un respetuoso ejemplo, sería como acomodar desde nuestra Iglesia las mismas palabras de Cristo para justificar cruzadas, inquisiciones, condenas, etc. No es lo mismo Marx que marxismo, Agustín que agustinismo, Lutero que luteranismo, Islam que Isis. Lo sesgos han existido en todas las estructuras humanas, la casta meretrix no es excepción. Ya el padre Alberto Parra ha elaborado una significativa apología ${ }^{22}$ digna de rescatar en la reafirmación de la identidad teológica latinoamericana.

18 Congregación para la Doctrina de la Fe, Instrucciones sobre la Teología de la Liberación, Madrid: BAC, 1986, 15.

${ }^{19}$ Ibíd., 16.

${ }^{20}$ Ibíd., 39.

${ }^{21}$ En las disertaciones sobre la historicidad de la salvación cristiana son muy pertinentes los aportes de Ignacio Ellacuría al tratar los conceptos fundamentales de la Teología de la Liberación. Según él, no hay una dicotomía entre Teología de la Liberación y Teología Política donde los temas teológicos se apartan de los temas humano políticos, sino que la Teología de la Liberación es una teología del Reino de Dios que los incorpora en una sola, no es lo político su centro, como tampoco lo es la liberación integral en sí misma, porque no son dos historias: la humana o la profana y la sagrada o de salvación, sino una sola: la humana donde acaece la salvación, donde se instaura el Reino de Dios a través de Cristo que diviniza nuestra naturaleza. Cfr. Ellacuría, Ignacio. "Historicidad de la salvación cristiana”, en: Ellacuría, I. - Jon Sobrino, Mysterium Liberationis. Conceptos fundamentales de la Teología de la Liberación, Madrid: Trotta, 1990, 323-372.

22 Parra, Alberto, "La Teología de la Liberación después de la Instrucción. Reafirmar su identidad", Theologica Xaveriana 73 (1984) 401-437. http://theologicaxaveriana.javeriana.edu.co/edicion.php?Ed=139\& $\mathrm{Cn}=5$ (Consultado el 18 de septiembre de 2017). Signi- 
Destacamos particularmente en este punto la reflexión de Rodolfo de Roux cuando hablando de la eclosión de las teologías de las realidades terrenas o contextuales y de género, da relevancia sobre todo a la Teología de la Liberación que según él "es digna de una vigencia permanente, más allá de las limitaciones y riesgos que haya podido sufrir en el tanteo de sus primeros pasos" ${ }^{23}$. El tiempo ha denunciado injustos juicios de valor hacia ella al reducirla a una especie de tratado sociológico de la religión o ideología de partidismo político; aplican sugerentemente entonces las palabras de Rafael Aguirre:

[...] hacer memoria del pasado puede convertirse en la mayor exigencia y en el más grande acicate para el cambio social, porque en el pasado laten posibilidades inéditas y perdidas, deudas no saldadas, huellas semiocultas, que las historias oficiales nunca han sacado a la luz. Por supuesto, cuando miramos atrás descubrimos trigo y paja, líneas y opciones muy diversas; percibimos alternativas que de haber prevalecido hubiesen desembocado en un radicalismo exaltado y minoritario, o en grupúsculos especulativos. Pero, dicho con todas las cautelas, rescatar los pasados ocultos, hacer justicia a las víctimas, recuperar las verdades de los perdedores es lo que más hondamente impulsa para que el futuro no sea la simple prolongación del presente como obra de los vencedores. Con otras palabras, se trata de enriquecer el presente con la incorporación de nuevas perspectivas, de descubrir aspectos válidos y olvidados de la gran tradición cristiana" 24 .

Nos preguntamos entonces, si tal persecución por parte del mismo Vaticano y de jerarcas latinos, ¿no hizo parte de una forma de martirio incruento a través de reprensiones y vetos que buscaron ahogar una justa

ficativa y remota apología que como aporte teológico ofrece un fundamento hermenéutico en la búsqueda de lo que el teólogo Fernando Castrillón llama nuevas perspectivas hermenéuticas que permitan orientar una praxis liberacionista que, solo por la gracia de Dios, pueda ir más allá de los límites de las posibilidades humanas, campo al cual se reduce el pensamiento utópico. Cfr. Castrillón, José Fernando, Escatología de la Liberación. Pensamiento utópico y Teología de la Liberación, Bogotá: Editorial PUJ, 2016, 14.

23 De Roux, Guerrero Rodolfo, Facultad de Teología, 75 años, Bogotá: Pontificia Universidad Javeriana, 2012, 112.

${ }^{24}$ Aguirre Monasterio, Rafael (ed.). Así empezó el cristianismo, Estella: Verbo Divino, 2010, 24 
preocupación contextual en el ámbito de los eclesial y de lo social? Norbert Arntz en el libro conmemorativo de los cincuenta años del Pacto de las Catacumbas afirma que, refiriéndose a Medellín, la Curia romana buscó desarrollar una campaña para denunciar la conferencia en mención y todo otro compromiso de lado de los pobres, "preparó la conferencia de Puebla para 1979 con la intención de denunciar Medellín como infiltrada por el marxismo. El posterior cardenal Alfonso López Trujillo desempeñó aquí un papel decisivo (...). No obstante, los hombres que habían alentado el Pacto y habían hecho posible Medellín estaban presentes en Puebla y no se dejaron manipular" 25 .

Gustavo Gutiérrez como padre de la Teología de la Liberación ${ }^{26}$ con base en la Conferencia de Medellín destaca que estamos en el umbral de una nueva época histórica en la que se percibe en el presente de Latinoamérica, la dolorosa gestación de una nueva civilización. Como elemento teológico su aporte es muy considerable. "Me ha hecho mudar" 27 , fue la respuesta de Gutiérrez al preguntársele por la teología de la que es padre, en una entrevista concedida en el Segundo Congreso Continental de Teología celebrado en Brasil el año 2015.

Tal "mudar" teológico hace parte también de nuestra experiencia ante los desafíos posmodernos en la transmisión de la fe tal como lo plantea Hugo Assmann en uno de sus valiosísimos aportes teológicos de esencial referencia para la elaboración del presente trabajo:

"Si la situación histórica de dependencia y dominación de dos tercios de la humanidad, con sus 30 millones anuales de muertos de hambre y desnutrición, no se convierte en el punto de partida de cualquier teología cristiana hoy, aun en los países ricos y dominadores, la teología no podrá situar y concretizar históricamente sus temas fundamentales. Sus preguntas no serán preguntas reales. Pasarán al lado del hombre real. [...], es necesario salvar a la teología de su cinismo. Porque realmente frente a los problemas del

${ }^{25}$ Arntz, "Por una Iglesia servidora y pobre”, 121.

26 Gutiérrez, Gustavo, Teología de la Liberación. Perspectivas, Séptima Edición. Salamanca: Sígueme, 1975, 277-320.

27 Modino, Luis. Entrevista: "Gustavo Gutiérrez: jamás estuve condenado por la Congregación para la Doctrina de la Fe". (octubre de 2015), http://www.amerindiaenlared.org/congreso2015/documentos/ (Consultado el 15 de septiembre de 2017). 
mundo de hoy, muchos escritos de teología se reducen a un cinismo" 28 .

Con lo anterior es posible evidenciar indirectamente que la preocupación de los cuarenta obispos presentes en el Pacto de las Catacumbas atraviesa en el ámbito de lo espiritual la ortopraxis que demanda la elaboración teológica de la línea latinoamericana. No es posible hacer teología de espaldas al sufrimiento de los pobres y por lo tanto no es posible que un Pastor de la Iglesia aliente el caminar de su rebaño siendo ajeno a sus preocupaciones, tristezas, fracasos, anhelos gozos y esperanzas si él mismo no es capaz de anonadarse a la sencillez, humildad y pobreza de los suyos.

Para Jon Sobrino es la experiencia de resurrección en esta historia como seguimiento de Jesús que libera y redime a las víctimas de las estructuras de injusticia, terror y muerte: "la resurrección de Jesús es esperanza en primer lugar para los crucificados de la historia (...), por ello podrán tener el coraje de la esperanza en su propia resurrección, y podrán tener ánimo de vivir ya en la historia, lo cual supone un milagro análogo a lo acaecido en la resurrección de Jesús. Existe pues una correlación entre resurrección y crucificados, análoga a la correlación entre reino de Dios y pobres" 29 .

José Antonio Pagola en el libro conmemorativo de los cincuenta años del Pacto de las Catacumbas recoge de manera precisa la influencia del Pacto en el Magisterio de Francisco. Afirma que el obispo de Roma viene criticando en múltiples ocasiones la autorreferencia de la Iglesia al verla en muchas ocasiones encerrada en sí misma y paralizada, clausurada en una maraña de obsesiones y procedimientos, enferma por el encierro y la comodidad de sus seguridades ${ }^{30}$. También Agenor Brighenti en su análisis del Pacto, trabajo recogido en el mismo libro conmemorativo, destaca dos soplos del Espíritu que se desprenden del Pacto saliendo de las catacumbas: Aparecida y la elección de Francisco. Celebrada en 2007 el 1976, 40.

${ }^{28}$ Assmann, Hugo, Teología desde la praxis de la Liberación, Salamanca: Sígueme,

${ }^{29}$ Sobrino, Jon, La fe en Jesucristo: Ensayo desde las víctimas, Madrid: Editorial Trotta, Tercera Edición, 2007, 70.

${ }^{30}$ Pagola, "Un Pacto para seguir a Jesús pobre, caminando con los pobres", en: Xavier Pikaza - José Antunes Da Silva (eds.), El Pacto de las Catacumbas, 139. 
documento conclusivo tuvo una redacción presidida por el entonces cardenal Bergoglio. Es interesante cuando señala que Aparecida suscitó una reacción de censura en la Curia romana, el documento original conclusivo aprobado por la Asamblea de Obispos sufrió aproximadamente doscientos cincuenta cambios, unos cuarenta de ellos muy importantes ${ }^{31}$. En cuanto a la elección de Francisco señala Brighenti que inició un tiempo nuevo con exigencias impuestas a sí mismo:

(...) pagando sus cuentas al día siguiente de su elección, simplificando su atuendo, cambiando el trono por una silla, conservando su cruz pectoral y sus zapatos negros, renunciando a vivir en el palacio apostólico, utilizando un coche modesto. Es la manifestación viva de haber asimilado la famosa amonestación que san Bernardo dirigió a su cohermano cisterciense elegido para convertirse en el papa Eugenio III: «No te olvides de que eres sucesor de un pescador, no del emperador Constantino» ${ }^{32}$.

Su ejemplo cautiva e interpela, ha pedido a los jerarcas no ser carreristas y cortesanos, hombres que no tengan psicología de príncipe, pidiendo a los trepadores irse para los Alpes al considerarlo más saludable ${ }^{33}$. Quizá el discurso en tono mordaz más significativo a la figura de una pastor fue su crítica a los quince males de la Curia romana al finalizar el Adviento el 22 de diciembre de 2014: el creerse indispensable, el activismo, la planificación excesiva, el Alzheimer espiritual, la rivalidad y vanagloria, la esquizofrenia existencial, la divinización de los jefes, la indiferencia, la acumulación, los círculos cerrados, etc., sin duda una fuerte crítica al clericalismo en la variedad de sus facetas.

En el contexto de su visita a Colombia en septiembre de 2017 y dirigiéndose a los obispos les exhortó: "no se midan con el metro de aquellos que quisieran que fueran sólo una casta de funcionarios plegados a la dictadura del presente (...), solo Dios es Señor y a ninguna otra causa se debe someter nuestra alma de pastores" ${ }^{34}$. El ecuménico e interreligioso

\footnotetext{
${ }^{31}$ Brighenti, Agenor. "El Pacto de las Catacumbas y la tradición eclesial liberadora", en: Xavier Pikaza - José Antunes Da Silva (eds.), El Pacto de las Catacumbas, 223.

32 Ibíd., 226.

${ }^{33}$ Francisco, Homilía en la casa de santa Marta, mayo 6 de 2014.

${ }^{34}$ Francisco. Homilías y Discursos. Visita Apostólica a Colombia, Bogotá: CEC, 2017, $31-32$.
} 
magisterio de Francisco nos da un claro testimonio de apropiación compasiva de la historia en la búsqueda del bien común de la humanidad: el año jubilar de la misericordia, sus declaraciones sobre todo en su encíclica Laudato si, sobre el amor a la creación y su exhortación apostólica Amoris laetitia, sobre el amor a la familia, nos abren el panorama para interpelarnos y buscar una adecuada transmisión de la fe como verdaderos pastores. En palabras del mismo Francisco de Asís de quien el actual pontífice quiso adoptar su espiritualidad, el pastor ha de ser ante todo un Evangelio viviente a ejemplo de Aquel que por nosotros en profundo anonadamiento se encarnó.

Para finalizar esta segunda parte sobre la espiritualidad del Pacto en la Teología de la Liberación y en el Magisterio de Francisco, Jorge Costadoat en el mismo libro conmemorativo afirma lo siguiente:

El Pacto es un acto religioso y evangélico que expresa germinalmente la comprensión que la Iglesia haría de uno de los concilios más importantes de su historia. Por ello, no debe extrañar que años más tarde esta Iglesia terminara por madurar, formular y reiterar en cuatro conferencias episcopales su convicción mística y teológica más profunda: la opción de Dios por los pobres. Este es el nombre de la recepción que la Iglesia latinoamericana hizo del Vaticano $\mathrm{II}^{35}$.

Destacamos por lo tanto el talante práctico y liberador de la fe y la esperanza cristiana que han sido asumidos en su profundidad por la teología latinoamericana y el pontificado de Francisco. En profunda comunión pastoral y teológica, nuestra preocupación se ha inscrito dentro de aquello que en el ámbito del Magisterio profesaron nuestros pastores en las distintas conferencias del episcopado latinoamericano y desde el contexto eclesial actual en el que se pide una Iglesia compasiva en salida capaz de llegar a toda periferia, en cabeza de nuestros pastores.

${ }^{35}$ Costadoat, Jorge. "Pacto de las Catacumbas. La más latinoamericana de las teologías”, en: Xavier Pikaza - José Antunes Da Silva (eds.), El Pacto de las Catacumbas 231. 


\section{c) Un aporte de lectura al Pacto desde la espiritualidad agustiniana.}

El legado patrístico en continuidad con la Tradición de la Iglesia universal sigue siendo imprescindible en la elaboración de la teología, buscando los senderos de la verdad y la justicia evangélicos en los signos de los tiempos del presente con la ayuda en parte del patrimonio y la herencia de los patriarcas del pasado. Dada nuestra cercanía espiritual con el doctor de la Gracia, San Agustín de Hipona, intentaremos dar una lectura teológica en orden a la pobreza de los pastores desde su testamento teológico y del que ha sido depositaria la Orden que lleva su nombre.

El sermón $46^{36}$, dirigido a los pastores es sin duda uno de los sermones que, no solamente en el ámbito del rezo del oficio divino se medita anualmente, sino que analizado en su teología hace parte esencial de la delicada conciencia de pastor que rescataron los cuarenta obispos reunidos en las catacumbas de Domitila, allí decidieron caminar con los pobres, asumir un estilo de vida sencillo, propio de los pobres, renunciando no solamente a los símbolos de poder, sino al mismo poder externo, para retomar así el primer impulso misionero de la Iglesia en el mundo actual, era el año 1965, marcado por la dura lucha económica y la opresión general de los pobres ${ }^{37}$.

Con base en el texto de la profecía de Ezequiel 34,1-16, San Agustín elabora una crítica a los pastores que se apacientan a sí mismos tomando la leche de sus ovejas, cubriéndose con su lana, sacrificando las más fecundas, sin robustecer las débiles, sin curar las enfermas, sin buscar las perdidas, acabando con las fuertes y dispersando todo el rebaño. Al realizar un pequeño análisis de su escrito confronta el pasaje veterotestamentario

${ }^{36}$ San Agustín, Obras completas, Sermón 46. Guillermo Baoyi afirma que según la cronología de la producción agustiniana del padre José Anoz, este sermón fue predicado por San Agustín en el año 407 o 408 en Hipona o Cartago. Otras fuentes apuntan a que existen dudas acerca del año en que fue pronunciado este sermón. Algunas teorías lo sitúan entre los años 409 y 411, otras un poco antes. Algunos afirman que fue pronunciado en el año 407, lo que sería coherente con el aniversario de su ordenación episcopal, en el año 397. San Agustín habría celebrado dicho aniversario pronunciando un sermón sobre la naturaleza de la misión del Pastor. Cf. Baoyi, Guillermo. Análisis del sermón 46 de San Agustín sobre los pastores. Disponible en: https://guillermobaoyi.wordpress.com/2011/12/02/anlisisdel-sermn-46-sobre-los-pastores/;http://artedepredicar.com/sermones/item/86serm \% C3\%B3n-sobre-los-pastores-serm\%C3\%B3n-46-ccl-41-529-538. (Consultado el 20 de octubre de 2017)

${ }^{37}$ Pikaza, "Presentación del libro conmemorativo", 17. 
con el texto paulino en el que el Apóstol pide trabajar con las propias manos para no ser gravoso a nadie y concluirlo a través de una analogía con lo que debería ser la voz de un verdadero pastor y no lo contrario que a partir de la Escritura misma es comparado con un lobo disfrazado de mansa oveja. Creemos profundamente que en el contexto histórico del siglo XX aquellos obispos del Pacto no podían soportar el dolor y la tristeza de dos tercios de la humanidad sumidos en profunda pobreza, sería necesario un místico acto y compromiso de compasión y misericordia que buscara apacentar, en actitud de metanoia y kénosis, el sufrimiento del herido rebaño.

Valorando tan significativo sermón que atañe a una lectura espiritual de la figura del pastor, lo que particularmente quisiéramos rescatar también del obispo de Hipona es su intuición carismática plasmada en su Regla monacal a partir de la lectura de los Hechos de los Apóstoles en 2, 44 y 4, 32 - 35. Estos dos textos neotestamentarios son la base fundacional del carisma agustiniano, con los monasterios fundados por él mismo a finales del siglo IV y la posterior fundación de la Orden de Ermitaños de San Agustín en el siglo XIII que incorporó al igual que las otras ordenes mendicantes como los franciscanos y los dominicos, la orden presbiteral en muchos de sus frailes y por lo tanto la consecuente elección de algunos de sus miembros como llamados al episcopado.

Los trece numerales del Pacto poseen uno que es centro de atención a nuestro interés teológico. El numeral 10 dice lo siguiente:

Haremos todo lo posible para que los responsables de nuestro gobierno y de nuestros servicios públicos decidan y pongan en práctica las leyes, estructuras e instituciones sociales que son necesarias para la justicia, la igualdad y el desarrollo armónico y total de todo el hombre y de todos los hombres, y, así, para el advenimiento de un orden social, nuevo, digno de hijos de hombres y de hijos de Dios. Cf. Hch 2,44; 4, 32-35; 5,4; 2 Cor 8-9; 1 Tim. 5,1638.

Xabier Pikaza afirma que las citas bíblicas del Pacto puestas por los mismos obispos forman una especie de "florilegio evangélico sobre la pobreza (...), a partir de ellas puede elaborarse un evangelio de la po-

${ }^{38}$ Ibíd., 22. 
breza" ${ }^{39}$. Tales citas bíblicas no han sido añadidas al azar, justifican a la luz de la Palabra la bienaventuranza de la Pobreza comprendida en la medida de la Justicia, líneas atrás afirmábamos que comprendemos la Pobreza como kénosis del Señor, anonadamiento o abajamiento que trae como principal consecuencia la caridad oblativa que busca la Justicia y que en argumentos teológicos latinoamericanos llamamos ortopraxis, premisa sine qua non sería posible elaborar nuestra teología.

Con esta aclaración sobre la razón de las citas bíblicas allí puestas por los mismos obispos, retomamos la inspiración agustiniana que tiene como fundamento escriturístico las dos citas de Hechos de los Apóstoles. En su Regla monástica, el obispo de Hipona pone a Hch 4, 32-35 como el pilar bíblico del fin y el fundamento de la vida en común "lo primero por lo que se han congregado en Comunidad es para que vivan en la casa unánimes y tengan una sola alma y un solo corazón orientados hacia Dios" ${ }^{40}$. En el contexto histórico contemporáneo, no estrictamente monástico, en el que desde un convento que integra lo contemplativo y lo práxico desde la pastoral en sus diversas ramificaciones, muchos de los frailes que aspiran al presbiterado han de vivir prioritariamente este ideal de Hch 4, 32-35, aprender a compartir la vida y los bienes es la clave de inspiración en la predicación agustiniana, en ese sentido no es utópico, es una realidad que en convicción busca la justicia.

Es muy providencial que el Papa Francisco también se haya apoyado en ese texto a propósito de la primera jornada mundial de los pobres el 17 de noviembre de 2017 convocada por él y signo evidente de su opción preferencial por ellos, afirma lo siguiente:

"Estas palabras muestran claramente la profunda preocupación de los primeros cristianos. El evangelista Lucas, el autor sagrado que más espacio ha dedicado a la misericordia, describe sin retórica la comunión de bienes en la primera comunidad. Con ello desea dirigirse a los creyentes de cualquier generación, y por lo tanto también a nosotros, para sostenernos en el testimonio y animarnos a actuar en favor de los más necesitados" ${ }^{41}$.

\footnotetext{
${ }^{39}$ Pikaza, "Un Pacto bíblico”, 61.

${ }^{40}$ San Agustín, Regla monástica, 3.

${ }^{41}$ Francisco, I Jornada mundial de los pobres, Domingo 17 de noviembre de 2017.
} 
El padre Agostino Trapé de la Orden de San Agustín expresa lo siguiente, a propósito de esta convicción del carisma agustiniano: "es la forma de pobreza evangélica de la que los primeros cristianos dieron un ejemplo maravilloso y espléndido testimonio en Jerusalén (...). San Agustín ilustró y puso en práctica cuatro aspectos de esta pobreza evangélica, interpretada y vivida por los primeros cristianos: el voto, la renuncia a toda propiedad, la profunda vida común y la confiada espera de la misericordia de Dios" ${ }^{42}$. Ciertamente no se le podrá exigir a todo cristiano la estricta vida regular de un consagrado, un clérigo o un obispo, pero es posible a partir del testimonio de vida común enseñarles a compartir a ejemplo de las primitivas comunidades cristianas.

Lamentablemente en el auge de la Teología de la Liberación muchas Comunidades Eclesiales de Base fueron estigmatizadas. Es pertinente decir aquí con el aporte de Agenor Brighenti que al documento conclusivo de Aparecida los censores de la Curia romana "suprimieron algo que los obispos habían subrayado: «queremos reafirmar y dar un nuevo impulso a las CEB en el continente»"43. A pesar de todo es necesario decir que en tal experiencia de comunidades latinoamericanas, inspiradas por la espiritualidad de la Liberación, aún es posible testimoniar la comunión de vida que hizo bello el anuncio del Evangelio encarnándolo en las primitivas comunidades. Hacia esto apunta el numeral 10 del Pacto de las Catacumbas: "el advenimiento de un orden social, nuevo, digno de hijos de hombres y de hijos de Dios". La Civilización del Amor, en palabras de Pablo VI.

De la lectura espiritual anteriormente descrita nace el compromiso por lo social, el carisma agustiniano también ha querido sumarse a los esfuerzos de la identidad teológica latinoamericana, no han faltado los sesgos e injustas acusaciones cuando algunos frailes quisieron insertarse en latitudes de periferia, el clericalismo victimario dejo a muchos excluidos ante la nobleza de sus propósitos, sin embargo, es menester dar relevancia a algunos esfuerzos por parte de la Organización de Agustinos de Latinoamérica (OALA).

\footnotetext{
183-184.

42 Trapé, Agostino, La Regla de San Agustín, Madrid: Ed. Religión y Cultura. 1978,

${ }^{43}$ Brighenti, "El Pacto de las Catacumbas y la tradición eclesial liberadora", 224.
} 
La V Asamblea del Consejo de la OALA reunida en Belo Horizonte el año de 1977 afirmó que "San Agustín, a lo largo de su vida, de su obra literaria y de su ideal de vida monástica opta por el pobre y le interpreta como un privilegio, al ser la mejor expresión viva del Señor. Algunos hechos más significativos de su pastoral y casi todos sus sermones lo ponen de manifiesto" 44 . Tampoco ha faltado la necesaria crítica a un sistema de confort comunitario, el curso sabático de Lima en 1977 lo pone en evidencia: "se constata predominantemente la presencia de los agustinos en sectores adinerados o donde los valores de la comodidad, el lucro y los intereses prevalecen, a pesar de que existan también compromisos en sectores menos favorecidos" 45 .

La cuarta Asamblea del Consejo de la OALA reunida en México el año de 1975 destaca: "creemos que aún la orientación mayoritaria de nuestras comunidades no van en dirección de los menos favorecidos, aún gran parte de nuestras obras e instituciones permanecen instaladas en servicios a las clases dominantes" ${ }^{46}$. La sexta Asamblea de Iquitos en 1979 destaca: "En términos generales los agustinos no conocemos adecuadamente la realidad del mundo en que vivimos y nuestros puntos de vista de la misma están influenciados por los criterios de las clases con que trabajamos, preferentemente del nivel medio alto"47.

Muy significativas son las recomendaciones que da la primera Asamblea de la OALA reunida en Quito el año de 1969:

"Es de urgente necesidad para nuestra labor hoy que nuestras comunidades se entreguen al estudio de los documentos de la Iglesia y de nuestra Jerarquía de América Latina, y tomen conciencia de las necesidades de nuestro Continente, denunciadas en los documentos de Medellín, y de las posibilidades pastorales allí abiertas (...). Igualmente, la doctrina de San Agustín y de la espiritualidad de la Orden tienen que ser tema de nuestro estudio, ya que son fuente segura para las soluciones de los problemas actuales de la Iglesia en nuestro Continente (...). Es preciso que en nuestros colegios, parroquias, residencias, etc., se promueva una inquietud respecto a los pro-

44 OALA. Vida Agustiniana en América. Selección de textos de la OALA (1970 1980), Iquitos: Centro de Estudios de la Amazonía, 1980, 12.

45 Ibíd., 39.

${ }^{46}$ Ibíd., 41.

${ }^{47}$ Ibíd., 43. 
blemas de la Iglesia en América Latina señalados por las prioridades apostólicas dadas por el episcopado, es decir, promoción humana de los marginados, evangelización, pastoral universitaria, promoción de los laicos comprometidos y formación de comunidades de base" 48 .

Hemos querido recoger en estos extractos parte de las preocupaciones de algunos religiosos ante la situación de la Orden de San Agustín y su presencia en el continente Latinoamericano, en la línea de los anhelos de los obispos en las Catacumbas de Domitila y que fueron voz profética en la Conferencia de Medellín en 1968. Estos religiosos siguieron la línea profética de aquellos pastores. Con el presente trabajo hemos querido también hacer justicia a la voz de tantos hijos de Agustín que buscaron con sus preocupaciones y compromisos seguir la línea mística en la ortopráxis de los padres conciliares presentes en el Pacto de la Catacumbas y que se sumaron a la elaboración teológica latinoamericana aun cuando posteriormente fueron quizá perseguidos o vetados injustamente.

\section{Conclusiones}

Concluimos que el Pacto de las Catacumbas ha sido el sello místico del acontecimiento eclesial reformador más relevante del siglo XX como lo ha sido el Concilio Vaticano II, la Pobreza anclada en la ortopráxis es el argumento espiritual más profundo, columna vertebral que atraviesa la Teología de la Liberación en la pluralidad de sus facetas. Los obispos latinoamericanos presentes en el trascendental acontecimiento de las Catacumbas de Domilita han legado vitalmente a la Iglesia con una de las formas de respuesta más contundentes y desafiantes: la pobreza evangélica. De ella nos habla también con su testimonio el actual pontífice Francisco, su magisterio sin duda posee la identidad latinoamericana y con él está haciendo justicia al clamor de tantos pastores que han deseado tal humildad y sencillez. La celebración de la primera jornada mundial de los pobres es una profética invitación a toda la Iglesia a poner nuestra sincera mirada en las heridas de la humanidad y en hacer una opción preferencial por los que no tienen voz.

\footnotetext{
${ }^{48}$ Ibíd., 44.
} 
Lo significativo del Pacto de las Catacumbas, como hemos intentado desarrollarlo, ha sido su incidencia espiritual en la teología latinoamericana, el corazón del presente trabajo ha encontrado allí su punto de inspiración. Existe cierta espiritualidad en el Pacto que delineó la mística de lo que posteriormente se consideró como la teología de identidad amerindia desarrollada por una Iglesia que ad portas de sus quinientos años de evangelización llegaba a su adultez y madurez.

Finalmente hemos querido traer a colación el aporte de lectura al Pacto desde la espiritualidad agustiniana, también el legado del obispo de Hipona como Padre de la Iglesia sigue siendo un elemento de discernimiento en el constructo teológico contemporáneo, los hijos de su Orden como herederos de su espiritualidad no han sido ajenos a las preocupaciones de la Iglesia Latinoamericana y es un motivo de elogio teológico para la escuela agustiniana amerindia haber rescatado parte de sus alcances y logros.

\section{Anexo: Texto del Pacto}

"Nosotros, obispos reunidos en el Concilio Vaticano II, habiendo recibido luz sobre las deficiencias de nuestra vida de pobreza según el evangelio, nos comprometemos a lo que sigue:

1.- Intentaremos vivir según el modo ordinario de nuestra población en lo concerniente a la habitación, el alimento, los medios de locomoción y todo lo que con esto va unido (cf. Mt 5,3; 6,33-34; 8,2-20).

2.- Renunciamos para siempre a la apariencia y a la realidad de riqueza, especialmente en los vestidos (telas ricas, colores llamativos), las insignias de materias preciosas (estos signos deben ser realmente evangélicos: cf. Mc. 6,9; Mt 10,9-10; Hch 3,6).

3.- No poseeremos ni bienes inmuebles, ni muebles, ni cuentas bancarias, etc., a nuestro propio nombre; y si es preciso poseer, pondremos todo a nombre de la diócesis, o de las obras sociales o caritativas (cf. Mt. 6,19-21; Lc 12,33-34).

4.- Siempre que sea posible, confiaremos la gestión financiera y material en nuestras diócesis a un comité de seglares competentes y conscientes de su función apostólica, con el fin de ser menos administradores que pastores y apóstoles (cf. Mt 10.8; Hch 6,1-7). 
5.- Renunciamos a ser llamados de palabra o por escrito con nombres y títulos que indican grandeza y poder (Eminencia, Excelencia, Monseñor). Preferimos ser llamados con el nombre evangélico de Padre.

6.- En nuestro proceder y en nuestras relaciones sociales evitaremos lo que pueda dar a entender que damos privilegios, prioridad e incluso cualquier tipo de preferencia a los ricos y poderosos -v.gr., banquetes ofrecidos o aceptados, clases en los servicios religiosos- (cf. Lc 13,1214; 1 Cor 9,14-19).

7.- Igualmente evitaremos fomentar o adular la vanidad de nadie con la intención de recomendar o solicitar dones, o por cualquier otro motivo. Invitaremos a nuestros fieles a considerar sus aportaciones como una participación normal en el culto, en el apostolado y en la acción social (cf. Mt 6,2-4; Lc 15,9-13; 2 Cor 12,14).

8.- Daremos cuanto sea necesario de nuestro tiempo, reflexión, corazón, medios, etc., al servicio apostólico y pastoral de las personas y grupos trabajadores y económicamente débiles y subdesarrollados, sin que esto perjudique a los demás grupos y personas de la diócesis. Apoyaremos a los seglares, religiosos, diáconos o sacerdotes que el Señor llame a evangelizar a los pobres y obreros participando de la vida obrera y del trabajo (cf. Lc 4,18; Mc 6,4; Mt 11,45; Hch 18,3-4; 20,33-35; 1 Cor 4,12; 9,1-27).

9.- Conscientes de las exigencias de la justicia y de la caridad y de sus relaciones mutuas, intentaremos transformar las obras de beneficencia en obras sociales basadas sobre la caridad y la justicia, que tengan en cuenta a todos las exigencias, como un humilde servicio a los organismos públicos competentes (cf. Mt 25,31-46; Lc 13,12-14 y 33-34).

10.- Haremos todo lo posible para que los responsables de nuestro gobierno y de nuestros servicios públicos decidan y pongan en aplicación las leyes, las estructuras y las instituciones sociales necesarias para la justicia, la igualdad y el desarrollo armónico y total de todo el hombre y de todos los hombres y, por este camino, para el establecimiento de un orden social distinto, nuevo, digno de hijos del hombre y de hijos de Dios (cf. Hch 2,44-45 y 4,32-35; 2 Cor 8 y 9 ; 1 Tim 5,16).

11.- Puesto que la colegialidad de los obispos encuentra su más evangélica realización en el interés común por las masas en estado de miseria física, cultural y moral (los dos tercios de la humanidad), nos comprometemos: - a participar, en la medida de nuestras posibilidades, en las inversiones urgentes de los episcopados de las naciones pobres; - a conseguir juntos, en el plano de los organismos internacionales, pero como testimo- 
nio del evangelio, como el papa Pablo VI en la ONU, la puesta en marcha de estructuras económicas y culturales que no fabriquen naciones proletarias en un mundo cada vez más rico, sino que permitan a las masas pobres salir de la miseria.

12.- Nos comprometemos a compartir con amor pastoral nuestra vida con nuestros hermanos en Cristo, sacerdotes, religiosos, seglares, para que nuestro ministerio sea un verdadero servicio. Por tanto: - nos esforzaremos en "revisar nuestra vida" con ellos; - suscitaremos colaboradores, con el fin de ser más bien animadores según el Espíritu que jefes según el mundo; - procuraremos que nuestra presencia sea más humana y acogedora; - nos mostraremos abiertos a todos, sea cual sea su religión (cf. Mc 8,34-35; Hch 6,1-7; 1 Tim 3,8-10).

13.- Vueltos a nuestras diócesis respectivas, daremos a conocer a nuestros diocesanos nuestra decisión, rogándoles nos ayuden con su comprensión, su colaboración y su plegaria. Que Dios nos ayude a ser fieles." 